ARTICLE

\title{
Mechanisms associated with the antidepressant-like effects of L-655,708
}

\author{
Vladislav Bugay ${ }^{1}$, Alexandra Maxine McCoy ${ }^{2}$, Daniel James Lodge $\mathbb{D}^{2,3,4}$, Robert Brenner ${ }^{1,3}$, Alan Frazer ${ }^{2,3,4}$ and Flavia Regina Carreno ${ }^{2,3}$
}

Previous research has demonstrated that selective modulation of hippocampal transmission by systemic administration of an a5$\mathrm{GABA}_{\mathrm{A}}$ receptor negative allosteric modulator, L-655,708, reproduces the sustained antidepressant-like (AD-like) effect of R,Sketamine in the absence of any psychotomimetic or abuse-related effects. Pharmacological, electrophysiological (whole-cell patch clamp), and behavioral approaches were used to examine the mechanisms by which L-655,708 produces plasticity within the hippocampus that accounts for its sustained AD-like effect in rats. Inhibitors of either transcription or translation prevented the sustained AD-like effect of L-655,708. Unlike R,S-ketamine, L-655,708 did not cause an increase in the phosphorylation of the receptor for BDNF, TrkB, in the ventral hippocampus (vHipp) 30 or $60 \mathrm{~min}$ after its administration nor did administration of the TrkB inhibitor, K252a, directly into the vHipp, block the sustained AD-like effect of L-655,708. Similar to previous results with R,Sketamine, administration of L-655,709 increased levels of GluA1 in the mPFC and, blockade of such receptors by direct administration of NBQX into the MPFC blocked the sustained AD-like effect of L-655,708. Patch-clamp recordings of ventral CA1 pyramidal cells $24 \mathrm{~h}$ after a single systemic administration of $L-655,708$ revealed a significant increase in input resistance, which resulted in an approximately two-fold increase in action potential frequency. These experiments indicate that the sustained $A D-l i k e$ effects of L-655,708 require protein synthesis and plasticity of GluA1 glutamate receptors in the mPFC. The drug also caused changes in $\mathrm{GABA}_{A}$ receptor gating properties in the vHipp with resultant changes in ventral CA1 that indirectly increases neuronal excitability. Such effects likely contribute to its sustained AD-like activity.

Neuropsychopharmacology (2020) 45:2289-2298; https://doi.org/10.1038/s41386-020-0772-2

\section{INTRODUCTION}

Brain regions classically associated with mood regulation and cognitive processing are the hippocampus (Hipp) and medial prefrontal cortex (mPFC), respectively [1-5]. The ventral hippocampus (vHipp) is widely connected to the limbic system, with robust glutamatergic projections to the $\operatorname{mPFC}[6,7]$. Classic antidepressants, R,S-ketamine and brain stimulation approaches to treat depression, have been reported to alter hippocampal and cortical function [8-10] and to promote antidepressant-like (ADlike) effects that are dependent upon activation of the brainderived neurotrophic factor (BDNF)-TrkB pathway [11, 12]. We previously reported that a pathway from the vHipp to the $\mathrm{mPFC}$ is both necessary and sufficient for the sustained AD-like effects of $R$, S-ketamine [13]. Consistent with this, it has been reported that brief high-frequency stimulation of the vHipp induced plasticity in the MPFC and such plasticity facilitated behavior dependent on mPFC function, i.e, cognitive flexibility [14]. Consequently, we hypothesized that acute pharmacological augmentation of vHipp activity by $L-655,708$, an a5-GABA $A$ receptor negative allosteric modulator (NAM), working through BDNF-TrkB activation, will enhance glutamatergic transmission in a pathway to the mPFC that will induce plasticity and contribute to AD-like effects.

$\mathrm{GABA}_{\mathrm{A}}$ receptors are pentameric comprised by two alpha $(a 1-6)$, two beta $(\beta 1-3)$, and one gamma $(\gamma 1-3)$ subunits [15].
Radioligand binding studies and mRNA expression data revealed that the a5-subunit of the $\mathrm{GABA}_{\mathrm{A}}$ receptor in the CNS is highly abundant in the hippocampus, both in rodents and humans [1619]. These receptors are classically believed to be extrasynaptic and localized to the base of dendritic spines of pyramidal neurons [20-23]. It is worth noting that although L-655,708 efficacy is about the same for all the alpha subunits of the $\mathrm{GABA}_{\mathrm{A}}$ receptor, the selectivity of $L-655,708$ for the a5 subunit at the benzodiazepine site is due to its higher binding affinity for a5 when compared to the other alpha subunits [24, 25].Thus, the a5containing $\mathrm{GABA}_{\mathrm{A}}\left(\mathrm{a} 5-\mathrm{GABA} \mathrm{A}_{\mathrm{A}}\right)$ receptor is positioned to be activated by GABA 'spillover' from adjacent synapses and provide a tonic inhibitory input to glutamatergic hippocampal projection neurons. As well, electron microscopy studies indicate that a5$\mathrm{GABA}_{\mathrm{A}}$ receptors cluster at CA1 synaptic GABA sites [26] and contribute to slow phasic GABA currents in $C A 1$ pyramidal neurons [27] and local inhibitory neurons of CA1 [17, 28]. Given the high localization of these receptors to the hippocampus and their role as mainly regulating inhibitory control over hippocampal output, they are an ideal candidate as a target for drugs that could act selectively on the hippocampus and cause disinhibition [29], albeit by a different mechanism than that of R,S-ketamine. Thompson and colleagues have shown that systemic administration of $L-655,708$ produces a sustained AD-like effect [30].

\footnotetext{
${ }^{1}$ Department of Cellular and Integrative Physiology, University of Texas Health Science Center, San Antonio, TX, USA; ${ }^{2}$ Department of Pharmacology, University of Texas Health Science Center, San Antonio, TX, USA; ${ }^{3}$ Center for Biomedical Neuroscience, University of Texas Health Science Center, San Antonio, TX, USA and ${ }^{4}$ South Texas Veterans Health Care System, Audie L. Murphy Division, San Antonio, TX, USA

Correspondence: Flavia Regina Carreno (Carrenof@uthscsa.edu)
}

Received: 11 March 2020 Revised: 18 June 2020 Accepted: 10 July 2020

Published online: 20 July 2020 
Moreover, the AD-like effects of $L-655,708$ are dependent on activation of the vHipp [31]. Our hypothesis is that L-655,708, acting at a5-GABA $A_{A}$ receptors of CA1 neurons, are targets of disinhibition that promote changes in the vHipp-mPFC pathway leading to AD-like effects. The studies described here included electrophysiological and behavioral approaches to assess the mechanisms by which pharmacological modulation of the hippocampus by L-655,708 produces its sustained behavioral effects.

\section{METHODS AND MATERIALS}

Animals

Experiments were carried out using adult male or female SpragueDawley rats purchased from Envigo and weighing, respectively $250-275 \mathrm{~g}$ or $175-199 \mathrm{~g}$ at the time of arrival unless otherwise stated. Rats were always group housed (3 per cage) and maintained in a temperature-controlled environment on a 14:10 h light-dark cycle and had access to food and water ad libitum. From the day of arrival, rats were given at least a week for habituation before beginning the studies. Experimental protocols were approved by the IACUC in accordance with the guidelines of the Public Health Service, American Physiological Society, and the Society for Neuroscience.

\section{Forced Swim Test (FST)}

For the pre-swim session, rats were placed into a Plexiglas cylinder tank $(21 \times 46 \mathrm{~cm})$ filled with water $\left(25^{\circ} \mathrm{C} \pm 1\right)$ and allowed in the tank for a period of $15 \mathrm{~min}$. For the test session, rats were placed into the same tank and water conditions as above, and behavior was digitally recorded by a video camera placed above the tank for a period of $5 \mathrm{~min}$. Only one rat was tested at a time. Lights were not dimmed, and no white noise was played. A time sampling technique was utilized where the most prominent behavior (immobility, swimming or climbing) observed in each $5 \mathrm{~s}$ bin was recorded for the $5 \mathrm{~min}$ of the test [32]. The behavioral raters were blind to the treatment conditions.

\section{Locomotor activity (Open field)}

Separate cohorts of male or female rats were injected with vehicle or L-655,708 (3 mg/kg, i.p.) and after $5 \mathrm{~min}$ placed into an open field arena (Med Associates, VT, USA) and spontaneous locomotor activity in the $\mathrm{x}-\mathrm{y}$ plane was determined for $1 \mathrm{~h}$ by beam breaks and recorded with Open Field Activity software (Med Associates).

\section{Anisomycin and actinomycin D experiment}

Separate cohorts of male rats were injected intraperitoneally (i.p.) with either vehicle (DMSO) or anisomycin $(50 \mathrm{mg} / \mathrm{kg})$, or actinomycin D $(0.5 \mathrm{mg} / \mathrm{kg}), 1 \mathrm{~h}$ before a vehicle (25\% DMSO/75\% saline, $1 \mathrm{ml} / \mathrm{Kg}$, i.p.) or $\mathrm{L}-655,708$ (3 mg/kg, i.p.) injection. FST was carried out $24 \mathrm{~h}$ later.

\section{Guide cannula placement}

Male rats were anesthetized with $4 \%$ isoflurane or with a cocktail of $75 \mathrm{mg} / \mathrm{kg} \mathrm{R,S-ketamine} \mathrm{and} 0.5 \mathrm{mg} / \mathrm{kg}$ medetomidine (intramuscular) and placed into a stereotaxic apparatus using blunt atraumatic ear bars. As previously described [13], in experiments aimed to target the vHipp, bilateral indwelling cannulae (Plastics One: C317G (2)- C/C distance of $10.4 \mathrm{~mm}, \mathrm{D} / \mathrm{V}-5.5 \mathrm{~mm}$ below plate) were implanted $2 \mathrm{~mm}$ dorsal to the vHipp (A/P -5.3 or $-5.6 ; M / L \pm 5.2$ ). In separate cohorts, to target the $\mathrm{MPFC}$, bilateral indwelling cannulae (Plastics One) were implanted $2 \mathrm{~mm}$ above the $\mathrm{mPFC}(\mathrm{A} / \mathrm{P}+3.0, \mathrm{M} / \mathrm{L} \pm 1.3, \mathrm{D} / \mathrm{V}-2.0)$ angled $10^{\circ}$ laterally. Guide cannulae were fixed in place with dental cement and four anchor screws. Once the cement was completely solid, the wound was sutured, and the rats allowed to recover for at least a week before further experiments. The rats were always kept group housed. For microinjections directly into the vHipp or the mPFC, injectors (Plastics One) extending $2 \mathrm{~mm}$ past the end of the indwelling cannulae were utilized.

\section{NBQX injections into the mPFC}

Male rats were brought from the housing unit to the behavior facility and allowed to acclimatize for at least $1 \mathrm{~h}$ before the administration of either L-655,708 (3 mg/kg, i.p.) or vehicle $(25 \%$ DMSO/75\% saline, $1 \mathrm{ml} / \mathrm{Kg}$, i.p). They were then brought back to the housing unit and $24 \mathrm{~h}$ after either L-655,708 or vehicle administration, rats were moved back to the behavior room and administered vehicle (saline, $0.5 \mu \mathrm{l}$; Sigma-Aldrich) or NBQX (300 $\mu \mathrm{M}, 0.5 \mu \mathrm{l}$; Tocris) directly into the MPFC via an injector that extended $2 \mathrm{~mm}$ past the end of the indwelling cannula. Injectors were left in place for 5 min before being removed. Five minutes after mPFC injections, the FST was carried out.

\section{$\mathrm{L}-655,708$ injections into the vHipp}

On the day of drug administration, male rats were brought from the housing unit to the behavior facility and allowed to acclimatize for at least $1 \mathrm{~h}$ prior to the pre-swim session. Approximately $2 \mathrm{~h}$ following the pre-swim, administration of either L-655,708 (30 or $90 \mathrm{ng} / 1 \mathrm{ul}$; Tocris, USA) or vehicle (5\% DMSO/95\% saline; 1ul; Sigma-Aldrich, USA) directly into each vHipp via an injector that extended $2 \mathrm{~mm}$ past the end of the indwelling cannula. Rats were brought back to the housing unit and tested in the forced swim test in the behavior room $48 \mathrm{~h}$ following treatment.

\section{K252a Injections into the vHipp}

As previously described [13], male rats were brought from the housing unit to the behavior facility and allowed to acclimatize for at least $1 \mathrm{~h}$ before the administration of either K252a $(0.5 \mathrm{ng}$; Calbiochem, San Diego, CA, USA) or $20 \%$ DMSO (0.5 $\mu$; SigmaAldrich) directly into each vHipp via an injector that extended $2 \mathrm{~mm}$ past the end of the indwelling cannula. Injectors were left in place for $5 \mathrm{~min}$ before being removed. Twenty minutes following vHipp injections, animals received systemic administration of L655,708 (3 mg/kg, i.p.) or vehicle ( $25 \%$ DMSO/75\% saline, $1 \mathrm{ml} / \mathrm{Kg}$, i.p.). Rats returned to the housing unit and were tested in the FST in the behavior room 7 days following treatment.

\section{Western blot analysis}

TrkB phosphorylation analysis. Separate cohorts of male rats were sacrificed by rapid decapitation $0.5 \mathrm{~h}$ or $1 \mathrm{~h}$ after receiving L655,708 (3 mg/Kg, i.p.) or vehicle (20\% DMSO/70\% saline, $1 \mathrm{ml} / \mathrm{Kg}$, i.p.) The brains were quickly removed and sectioned into $1 \mathrm{~mm}$ coronal slices. The vHipp (bilateral) was dissected out and stored at $-80^{\circ} \mathrm{C}$ until processed for western blot analysis as previously described [33]. The total lysate (up to $50 \mathrm{ug}$ ) was separated in an SDS-PAGE gel (Any kD ${ }^{\mathrm{TM}}$ Mini-PROTEAN ${ }^{\circledR} \mathrm{TGX}^{\mathrm{TM}}$ precast protein gel, Bio-Rad) and blotted onto a $0.2 \mu \mathrm{m}$ nitrocellulose membrane using the Turbo semi transfer system (Bio-Rad). Membranes were incubated at $4{ }^{\circ} \mathrm{C}$ overnight with the following primary antibodies: anti-pY705 TrkB [1:1,000 in 2.5\% bovine serum albumin (BSA) in Tris Buffered Saline containing 0.1\% Tween-20 (TBST), Abcam, Cambridge, MA], and anti-TrkB (full length, 1:5,000 in 2.5\% BSA in TBST, Neuromics, Edina, MN). Secondary antibodies tagged to peroxidase $(1: 10,000$ or $1: 20,000$ in $2.5 \%$ BSA in TBST, Sigma) were used to reveal immunoreactive bands using commercially available enhanced chemiluminescence substrate. Equal loading was confirmed using anti- $\beta$-actin (1:80, 000 in $1 \%$ BSA in TBST, Sigma-Aldrich A3854). Membranes were washed with TBST and incubated with a horseradish chemiluminescence kit (Pierce, Rockford, IL) followed by an exposure to X-ray film for detection. Antibodies were stripped using a commercially available stripping buffer (Thermo Scientific, USA), and then washed, blocked again and re-probed with antibodies for total TrKB. Thus, phosphorylated TrkB, and total TrkB were obtained from the same 
membrane. Densitometry analyses of immunoreactive bands for pTrkB or total TrkB were performed using the NIH Image J software from the scanned films. For normalization, densitometric arbitrary units obtained for pTrkB was divided by the ones measured for total TrkB.

GluA1 levels in crude mPFC synaptoneurosomes. Male rats were sacrificed by rapid decapitation $24 \mathrm{~h}$ after receiving L-655,708 (3 mg/Kg, i.p.) or vehicle ( $25 \% \mathrm{DMSO} / 75 \%$ saline, $1 \mathrm{ml} / \mathrm{Kg}$, i.p.) The brains were quickly removed and sectioned into $1 \mathrm{~mm}$ coronal slices. The mPFC (prelimbic and infralimbic; bilateral) was dissected out and pooled such that four MPFC (two per rat) were processed together immediately as follows. The four mPFC were homogenized in $1 \mathrm{ml}$ of homogenization buffer as described by [34] using a Potter-Elvehjem homogenizer, centrifuged at $1000 \times g$ for $5 \mathrm{~min}$, which removes nuclei and unlysed cells from the homogenate [35]. The resulting supernatant was centrifuged at $15,000 \times g$ for $20 \mathrm{~min}$. The pellet, containing the crude synaptoneurosome faction, was then resuspended in RIPA buffer and proteins separated in an SDS-PAGE gel followed by blotting onto a $0.2 \mu \mathrm{m}$ nitrocellulose membrane as described above in this session. The membrane was stained with Pounceau and incubated with an antibody against the GLUA1 subunit of the AMPA receptor (GluA1) (Millipore \#2263; 1: 1,000; overnight at $4{ }^{\circ} \mathrm{C}$ ). The secondary antibody was goat anti-mouse (Sigma-Aldrich A9917; $1: 30,000,1 \mathrm{~h}, \mathrm{RT})$. Membrane was washed with TBST and incubated with a horseradish chemiluminescence kit (Pierce, Rockford, IL) followed by exposure to X-ray film for detection. Antibodies were stripped using a commercially available stripping buffer (Thermo Scientific, USA), and then washed, blocked again and re-probed with antibody against $\beta$-actin $(1: 80,000$ in $1 \%$ BSA in TBST, Sigma-Aldrich A3854). Once again, the membrane was washed with TBST and incubated with a horseradish chemiluminescence kit (Pierce, Rockford, IL) followed by exposure to X-ray film for detection. Densitometry analyses of immunoreactive bands for GLUA1 or $\beta$-actin (loading control) were performed using the NIH Image J software from the scanned films. For normalization, densitometric arbitrary units obtained for GLUA1 was divided by the ones measured for $\beta$-actin.

Patch-clamp electrophysiology

Male rats were treated with a single administration of vehicle or L655,708 (3 mg/kg, i.p.). Twenty-four hours later, patch-clamp recording of CA1 neurons in brain slices was made using an extracellular solution consisting of (in mM) $124 \mathrm{NaCl}, 2 \mathrm{KCl}, 2$ MgSO4, $1.25 \mathrm{NaH} 2 \mathrm{PO} 4,2 \mathrm{CaCl}_{2}, 26 \mathrm{NaHCO}_{3}, 10$ Dextrose, and 0.4 Vitamin C. To prepare the slices, rats were initially anesthetized with isoflurane and then sacrificed using a guillotine. The brains were quickly transferred to an ice-cold cutting solution containing in mM 254 sucrose, $3 \mathrm{KCl}, 2 \mathrm{MgCl}_{2}, 2 \mathrm{CaCl}_{2}, 1.25 \mathrm{NaH}_{2} \mathrm{PO}_{4}, 10 \mathrm{~d}$ glucose and $24 \mathrm{NaHCO}_{3} .300 \mu \mathrm{m}$ horizontal sections of the brain that included the ventral CA1 pyramidal neurons were prepared with a Leica VT1000S vibratome (Leica Microsystems, Bannockburn, IL, USA). Sections were allowed to recover at $30^{\circ} \mathrm{C}$ for at least $1 \mathrm{~h}$ in an oxygenated $\left(95 \% \mathrm{O}_{2} / 5 \% \quad \mathrm{CO}_{2}\right)$ extracellular solution containing (in $\mathrm{mM}$ ) $124 \mathrm{NaCl}, 2 \mathrm{KCl}, 2 \mathrm{MgSO}_{4}, 1.25 \mathrm{NaH}_{2} \mathrm{PO}_{4}$, $2 \mathrm{CaCl}_{2}, 26 \mathrm{NaHCO}_{3}, 10$ d-dextrose and 0.4 vitamin C. Brain slices were continuously perfused with the extracellular bath solution during whole-cell patch-clamp recordings. Whole-cell recording pipettes with tip resistances between 4 and $7 \mathrm{M} \Omega$ were pulled from borosilicate glass capillaries (TW-150 F, World Precision Instruments, Sarasota, FL, USA) using the Sutter $\mathrm{P}$-87 puller (Sutter Instrument, Novato, CA, USA). For action potential recordings, pipettes were filled with a potassium gluconate-based internal solution containing in $\mathrm{mM}$ : 120 potassium gluconate, $20 \mathrm{KCl}$, $2 \mathrm{MgCl}_{2}, 10$ HEPES, 2 ATP, 0.25 GTP and 0.1 EGTA, with pH adjusted to 7.4 and osmolarity of 295 mOsm. Neurons were identified using infrared microscopy and a charge-coupled device camera.
Neurons were clamped in the whole-cell mode using the wholecell mode of a HEKA EPC10 feedback amplifier and Patchmaster software (HEKA Instruments, Lambrecht/Pfalz, Germany). To investigate the firing properties of neurons, current-clamp recordings were made from a $-80 \mathrm{mV}$ holding current and a 200pA current injection for a $0.5 \mathrm{~s}$ duration. Analysis of passive membrane properties of cells was made at the resting membrane potential. Input resistance and capacitance was measured from a hyperpolarizing current injection of $-20 \mathrm{pA}$ from a $-80 \mathrm{mV}$ holding current. The spike shape, half-width and spike threshold were measured from the first spike during a 90-pA current injection.

Conditions for measuring chronic L-655,708-induced changes in postsynaptic currents were identical as those for action potential recordings above except that pipet solution had a low chloride concentration $(6 \mathrm{mM} \mathrm{KCl})$ so that EPSCs (inward currents) and IPSCs (outward current) could be coincidently detected at $-40 \mathrm{mV}$ holding potential. QX $314(5 \mathrm{mM})$ was also added to the pipet solution to block voltage-dependent sodium channels. Tonic GABA currents were recorded at $-30 \mathrm{mV}$ in the presence of Kynurenic Acid (1 mM) to reduce excitatory neurotransmission and using current subtraction with either L-655,708 (L-655,708sensitive currents) or bicuculine (total GABA currents). Measurements of acute L-655,708-induced changes in excitatory currents in brain slices were measured using the gluconate-based internal solution described above. Action potentials and postsynaptic currents were measured using Axograph software.

\section{Data analyses}

All data are presented as mean ${ }^{+} /$- standard error of the mean (SEM). Immobility, swimming or climbing behaviors in the FST data were analyzed by one-way ANOVA followed by Dunnett's multiple comparisons test (Figs. 1a and 3) or by two-way ANOVA followed by Sidak's multiple comparisons test (Figs. 1b, 2a and 4b). Western blot data were analyzed by Mann-Whitney U test (Fig. 2b) or by One-way ANOVA followed by Dunnett's multiple comparisons test (Fig. 4a). Patch-clamp electrophysiology data (Fig. 5) were analyzed using Student's $t$ test. All tests were two-tailed, and significance was determined at $p<0.05$. Detailed statistical reporting is presented as supplemental tables in the supplementary information section.

\section{RESULTS}

We previously published that selective modulation of hippocampal transmission by systemic administration of L-655,708 produced a sustained AD-like effect in male rats in the absence of any psychotomimetic or abuse-related effects [31]. Here, in females also, L-655,708 was also found to cause a sustained AD-like effect in the forced swim test (FST) (Fig. 1a; Supplemental Table 1), as shown by a decrease in immobility and an increase in swimming behavior. L-655,708 administration was not associated with any motoric effects measured in the open field in either male or female rats (Supplemental Fig. 1; Supplemental Table 6).

We speculated that plasticity in the vHipp-mPFC pathway induced by $L-655,708$ seems essential for its AD-like effect. Therefore, we investigated if protein synthesis was involved in the AD-like effect of $L-655,708$. Pretreatment of male rats systemically with inhibitors of transcription (actinomycin $D$ ) or translation (anisomycin), prevented the sustained L-655,708induced effects in the FST measured $24 \mathrm{~h}$ following drug treatment (Fig. 1b; Supplemental Table 1). The inhibitors alone had no effect on immobility (Fig. 1b).

The next experiment examined more specifically if such plasticity involved AMPA receptors in the MPFC as has been shown for R,S-ketamine [34]. The AMPA receptor antagonist, NBQX, was administered directly into the mPFC $24 \mathrm{~h}$ after administration of $\mathrm{L}-655,708$ and just before behavioral testing in 
A
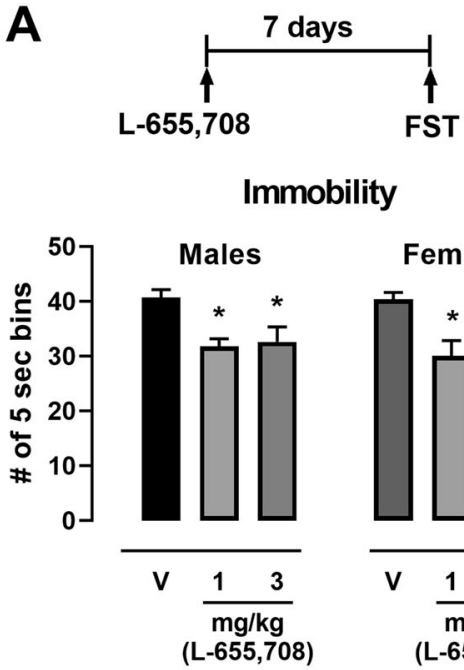

Females

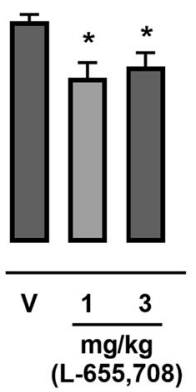

B anisomycin/actinomycin

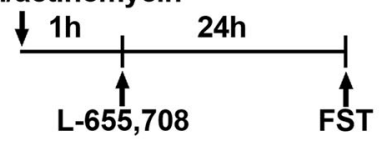

Immobility

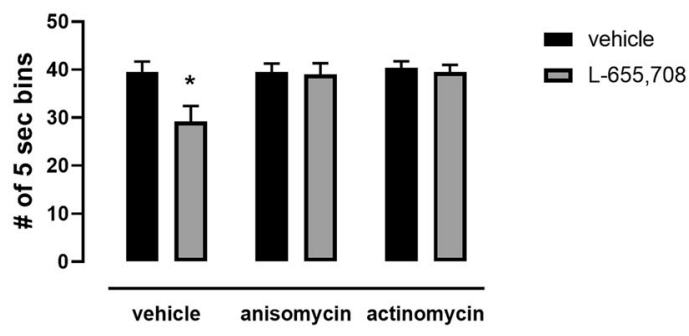

vehicle anisomycin actinomycin

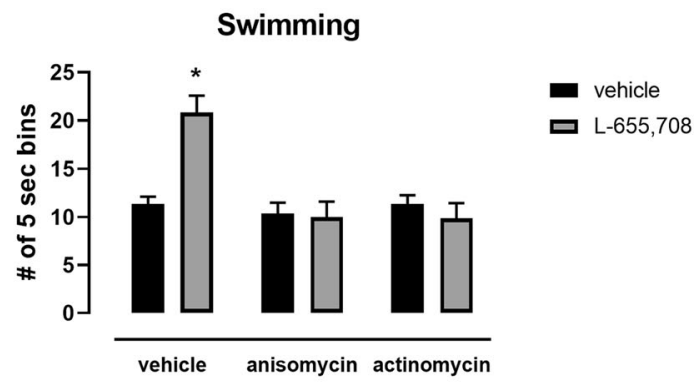

Females

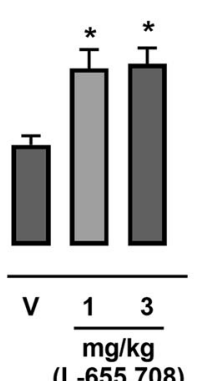

$(\mathrm{L}-655,708)$

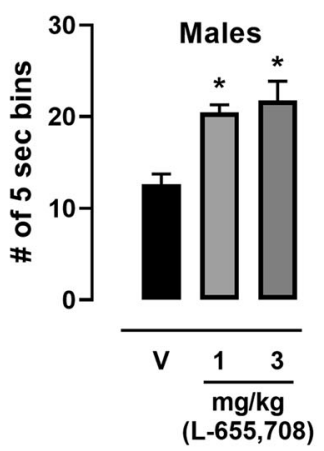

Swimming
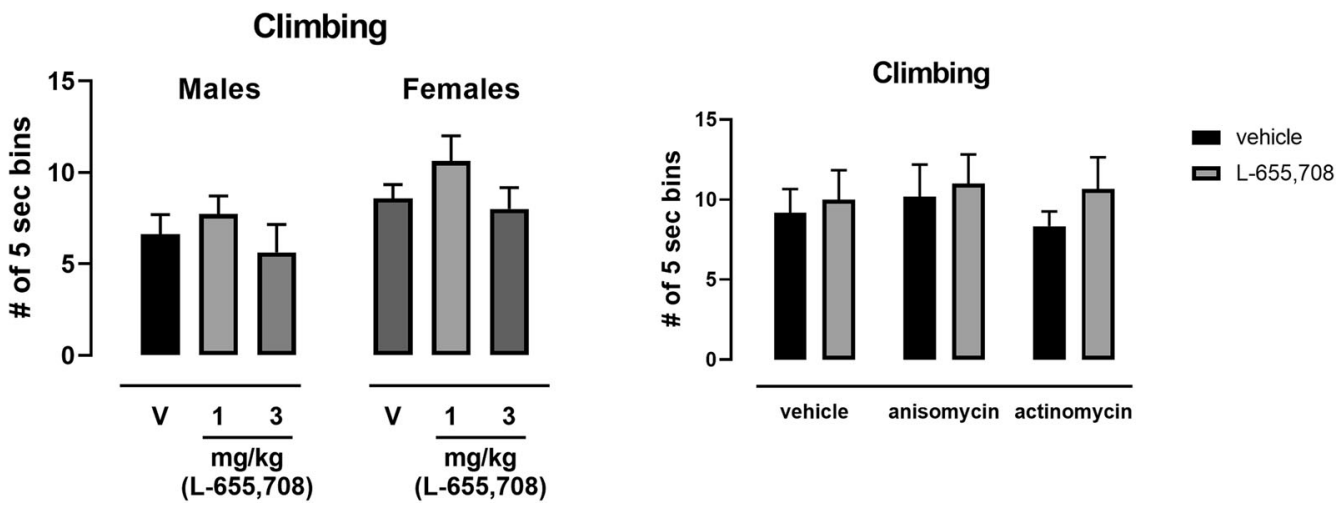

Fig. 1 The sustained AD-like effects of L-655,708 is transcription and translation dependent. a Separate cohorts of male and female rats were injected with L-655,708 or vehicle (V) and the FST was carried out 7 days after drug injection. Both 1 and $3 \mathrm{mg} / \mathrm{kg}$ of L-655,708 decreased immobility and increased swimming in the FST, ${ }^{*} p<0.05$ compared to control vehicle, $n=8-26$. b Inhibition of transcription and translation prevented the sustained AD-like effects of L-655,708 in the FST in male rats. Male rats were injected with L-655,708 $(3 \mathrm{mg} / \mathrm{kg}$, i.p.) or vehicle $1 \mathrm{~h}$ after pretreatment with anisomycin $\left(50 \mathrm{mg} / \mathrm{kg}\right.$, i.p) or actinomycin D $\left(0.5 \mathrm{mg} / \mathrm{kg}\right.$, i.p.). FST was performed $24 \mathrm{~h}$ after drug treatment. ${ }^{*} p<0.05$ compared to control vehicle; $n=6$.

the FST; this prevented the decrease in immobility and increase in climbing behavior produced by L-655,708 (Fig. 2a; Supplemental Table 2). Of some note is that whereas L-655,708 consistently decreased immobility in the rats, it does not have a consistent effect on swimming or climbing behavior (compare Figs. 1 and 2). Furthermore, treatment with L-655,708 produced enduring changes in AMPA receptor levels in the MPFC, as shown by increased levels of the GluA1 subunit of AMPA receptors in crude synaptoneurosomal fractions of the MPFC $24 \mathrm{~h}$ after treatment with L-655,708 (Fig. 2b; Supplemental Table 2).
Consistent with previous data that suggest the vHipp is the initial target for the effect of L-655,708 [31], local administration of $\mathrm{L}-655,708$ directly into the vHipp reproduced the sustained effect of systemic L-655,708 administration in the FST in a dosedependent manner (Fig. 3; Supplemental Table 3).

Activation of TrkB signaling pathway within the vHipp that could mediate L-655,708 sustained AD-like effects were also examined. In contrast to the involvement of BDNF/TrkB in the ADlike effect of R,S-ketamine [11], that of L-655,708 is not dependent upon TrkB phosphorylation in the vHipp. L-655,708 did not cause 
A

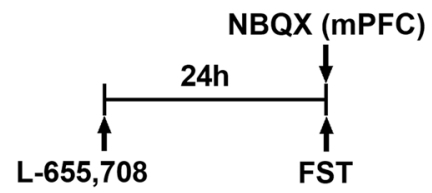

Immobility

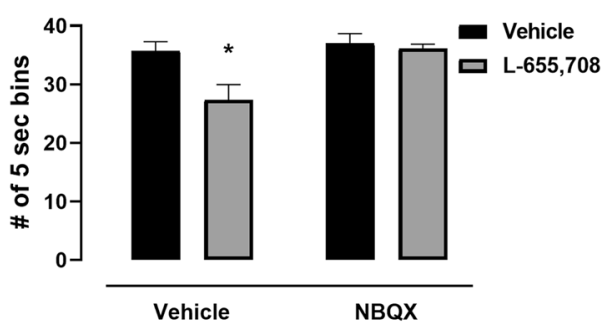

Swimming

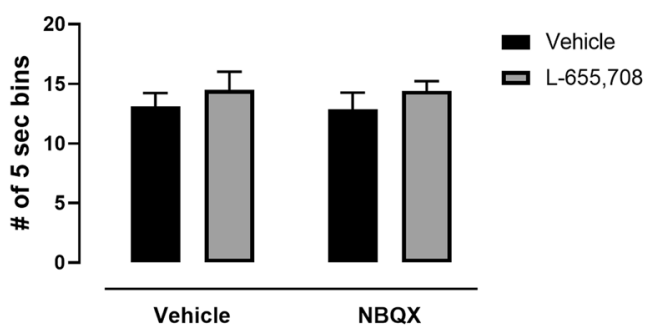

Climbing

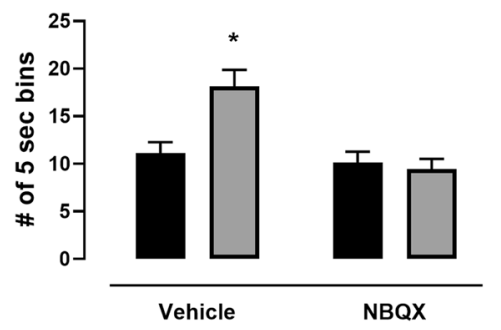

B

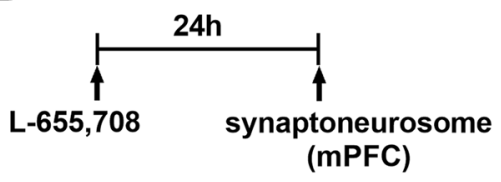

kDa L6 V V L6 V L6 V L6

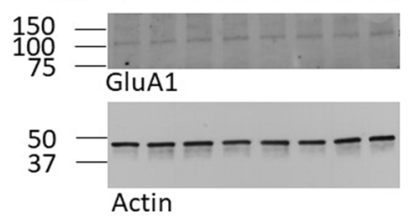

GluA1 levels

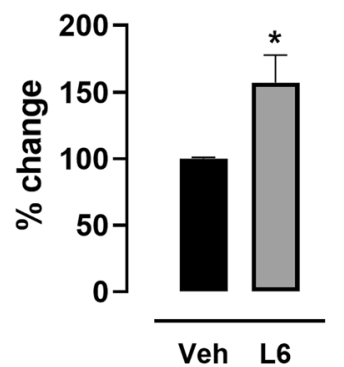

Fig. 2 The sustained AD-like effect of L-655,708 involves AMPA receptor plasticity in the mPFC. a Twenty-four hours after either L-655,708 $(\mathrm{L} 6,3 \mathrm{mg} / \mathrm{kg}$, i.p.) or vehicle (V) was given, male rats were administered vehicle or NBQX $(300 \mu \mathrm{M}, 0.5 \mu \mathrm{l})$ directly into the mPFC immediately before the FST was carried out. NBQX blocked the decrease in immobility and the increase in climbing produced by L-655,708; ${ }^{*} p<0.05$ compared to control vehicle, $n=7-8$. b L-655,708 produced increased levels of GluA1 in mPFC $24 \mathrm{~h}$ after administration of drug; ${ }^{*} p<0.05, n=4$.

an increase in the phosphorylation of TrkB in the vHipp either at 30 or $60 \mathrm{~min}$ after its administration (Fig. 4a; Supplemental Table 4) nor did intra-hippocampal administration of the TrkB inhibitor, K252a, block its sustained effect in the FST (Fig. 4b; Supplemental Table 4).

An electrophysiological approach was used next to determine if L-655,708 promotes functional changes in vHipp pyramidal neuron activity (Fig. 5) that might drive downstream plasticity in the mPFC. This was carried out using whole-cell patch-clamp recordings of pyramidal neurons in the vHipp using a low intracellular chloride solution to allow coincident detection of spontaneous glutamate-mediated inward cation currents, and GABA-mediated outward chloride currents (Fig. 5a). Twenty-four hours after systemic administration to rats of L-655,708 (3 mg/kg, i.p.) a reduction of the IPSC half-width was found. In rats administered L-655,708, there was an approximately 2.5-fold decrease in IPSC half-width (Fig. 5c; Supplemental Table 5), accompanied by a smaller decline of EPSC half-width (Fig. 5b; Supplemental Table 5) and reduction of IPSC amplitude (Fig. 5c;
Supplemental Table 5). Recordings of tonic GABA currents nevertheless indicated no significant effect of L-655,708 (Supplemental Fig. 2; Supplemental Table 7). Given changes in both EPSC and IPSC, the potential consequences were investigated in a separate cohort of rats using physiological solutions to record changes in voltage and action potential properties (Fig. $5 \mathrm{~d}$, e). The most profound effect was an increase of input resistance (Fig. 5e; Supplemental Table 5), which resulted in an approximately twofold increase in action potential frequency (Fig. 5d, e). These results are consistent with reduced chloride currents (reduced half-width) as a consequence of L-655,708 treatment in ventral CA1 neurons, initiating long-lasting changes that increased input resistance and increased excitability.

To confirm that L-655,708 can affect CA1 GABA currents to initiate long-lasting changes in excitability, we recorded acute effects of L-655,708 in hippocampal brain slices. While there were no direct effects on intrinsic excitability (Supplemental Fig. 3; Supplemental Table 8), we indeed found that $L-655,708$ reduced IPSC half-width and frequency (Supplemental Fig. 4A, B; 


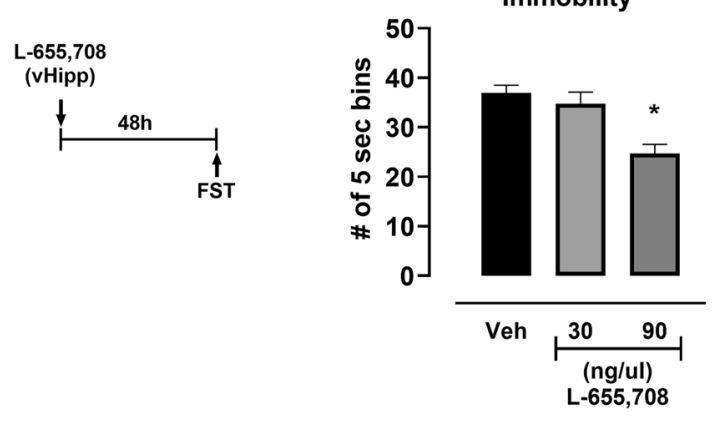

Swimming
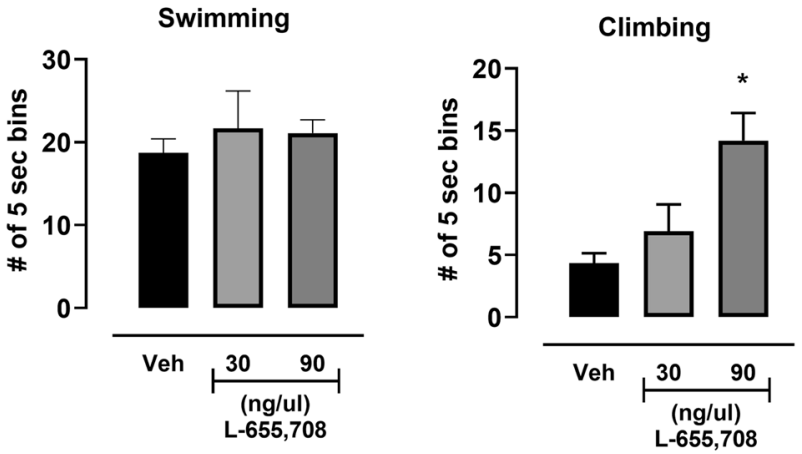

Fig. 3 L-655,708 (30 $\mathrm{ng}$ or $90 \mathrm{ng}$ per side; $1 \mu \mathrm{l}$ ) or vehicle (5\% DMSO in saline; $1 \mu \mathrm{l}$ ) was injected directly into the vHipp via guide cannula in male rats. FST was carried out $48 \mathrm{~h}$ later. A significant decrease in immobility and increase in climbing in the FST was produced by $90 \mathrm{ng}$ injection. ${ }^{*} p<0.05$ compared to control vehicle, $n=8-18$.

Supplemental Table 9). Although not significant, there was also a strong trend for L-655,708 effects on tonic currents $(P=0.06$, Supplemental Fig. 4C; Supplemental Table 9). Interestingly, we also observed an increase of EPSC current amplitudes and halfwidth (Supplemental Fig. 5; Supplemental Table 10), which, along with reduced inhibition, would further promote excitability in the CA1 neurons.

\section{DISCUSSION}

Consistent with previous studies [31], we found that a selective NAM of the a5-containing $G_{A B A}$ receptor, L-655,708, produced a behavioral response in the FST that is similar to those of other antidepressant drugs and that this response was sustained for up to 7 days after systemic administration. This effect is seen in both male and normal cycling female rats. In the MPFC, this response required protein synthesis and plasticity involving the GluA1 glutamate receptor. But in the vHipp, the antidepressant effect is independent of activation of TrkB receptors. Also, patch-clamp recordings from pyramidal cells in the vHipp revealed that $24 \mathrm{~h}$ after systemic administration of $L-655,708$ there was a robust decrease in the half-width of spontaneous IPSCs, indicative of reduced inhibition, as well as an approximately two-fold increase in stimulated action potential frequency. Taken together, these results are consistent with L-655,708 activating the vHipp to produce glutamate-induced plasticity in the MPFC that is related to its AD-like effect.

As originally described by Porsolt et al. [36], the FST is being used as an indicator of likely antidepressant efficacy, with predictive validity only, not as a measure of a component of depression, e.g., despair or helplessness. As with all such indicators, it has limitations, and some compounds that generated positive results in the FST have not demonstrated efficacy in clinical testing $[37,38]$. To the best of our knowledge, all drugs that are used clinically for depression have yielded positive results in the FST [38]. Of interest is that the FST detects the sustained antidepressant effect of R,S-ketamine following single administration [11, 13], similar to its sustained antidepressant effect in the clinic following a single intravenous administration. More traditional antidepressants have to be given multiple times to produce a positive result in the FST as is so for their clinical use. L-655,708 also has a sustained effect in the FST [30, 31], and like R,Sketamine, restored, after a single administration, stress-induced deficits in social interaction and in sucrose preference [30].

It has been demonstrated that antidepressant drugs acting primarily via the serotonergic system, such as SSRIs, will decrease immobility time in the FST with a parallel increase in swimming behavior [32]. By contrast, noradrenergic antidepressants increase climbing rather than swimming behavior. As neither ketamine nor $\mathrm{L}-655,708$ act primarily through these biogenic amine systems, it is perhaps not surprising that they do not show consistent effects on either swimming or climbing ([13]; present results).

Even though it is an NMDA glutamatergic receptor antagonist, a consequence of R,S-ketamine's administration is enhanced glutamatergic transmission in hippocampal terminal fields, particularly through non-blocked AMPA receptors. Considerable experimental evidence supports this idea [39]. Moreover, consistent with R,S-ketamine's effect, L-655,708 promotes glutamatergic plasticity, namely, it rapidly reversed stress-induced deficits in AMPA receptor signaling in the hippocampus [30].

One of the metabolites of R,S-ketamine, namely (2R,6R)-hydroxynorketamine, which is not an NMDA receptor antagonist, also produces glutamatergic plasticity in the mPFC that seems to be necessary for its AD-like effect [40]. It may be that a common effect of novel antidepressants with sustained effects is their ability to produce glutamatergic plasticity in the $\mathrm{MPFC}$ irrespective of their initial target. In view of this, it is of interest that a5-GABA $A$ receptor NAMs, such as L-655,708, also increased GluA1 levels in the mPFC and directly applying the AMPA receptor antagonist, NBQX, into the mPFC at the time of testing antagonized its AD-like effect.

The initial target for $L-655,708$, namely $a-5 G A B A_{A}$ receptors, is different from that for $\mathrm{R}, \mathrm{S}$-ketamine so it is perhaps not surprising that they are producing different cellular effects in the vHipp. Whereas the AD-like effect of $R, S$-ketamine is dependent on TrkB activation $[11,13]$, our present results show that is not so for L655,708 . Further experiments will be necessary to clarify possible effects of $L-655,708$ in the vHipp that could produce cellular glutamatergic plasticity in the mPFC. Again, though, R,S-ketamine, 2R,6R-hydoxynorketamine, and L-655,708 all have AD-like activity dependent on AMPA receptor activation [30, 40, 41].

Although the cellular mechanisms that cause $L-655,708$ to activate the hippocampus leading to glutamatergic plasticity in the mPFC are unknown, it is reasonably well established that increased activity of glutamatergic neurons innervating the MPFC could lead to plasticity $[14,42]$. To see if such activation occurred, patch-clamp electrophysiological recordings of slices containing pyramidal cells of the vHipp were carried out. Such experiments revealed a marked increase in action potential frequency measured $24 \mathrm{~h}$ after drug administration. Such activation of glutamatergic hippocampal efferent neurons may well produce the glutamatergic plasticity seen in the mPFC. Interestingly, we found these effects do not occur with acute exposure of brain slices to $L-655,708$, which strongly suggest that disinhibition of CA1 neurons, where a5-GABA $A_{A}$ receptors are enriched, have indirect effects promoting plastic increases of intrinsic excitability. The mechanism requires further study. Although a5-GABA receptors modulate inhibitory transmission directly on CA1 neurons, these receptors also reside on inhibitory interneurons within CA1 [17] which might also have a role in anti-depressant effects of L-655,708. 
A

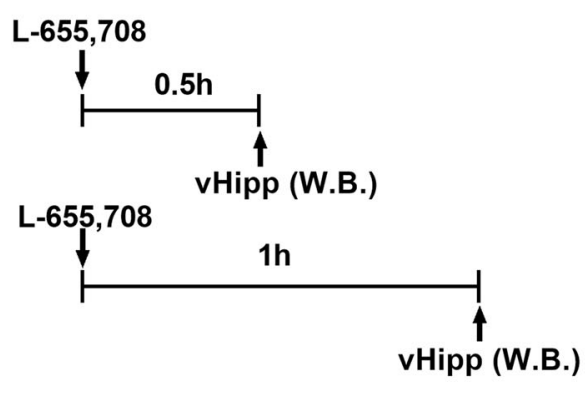

pTrkB/TrkB

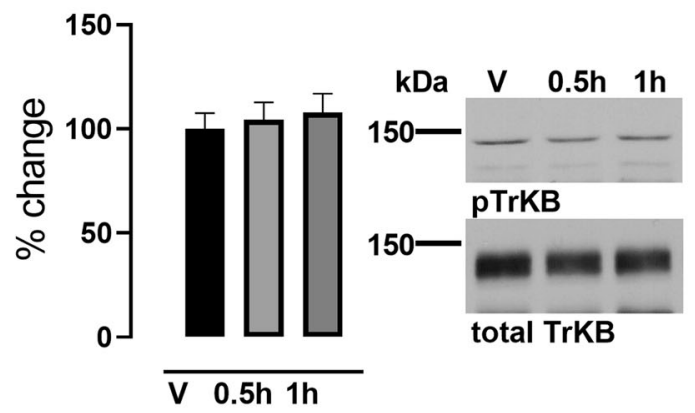

B

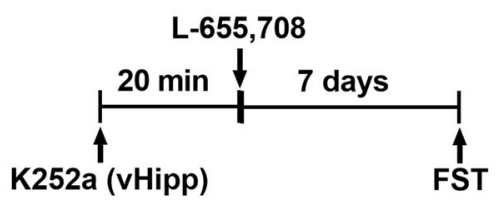

Immobility

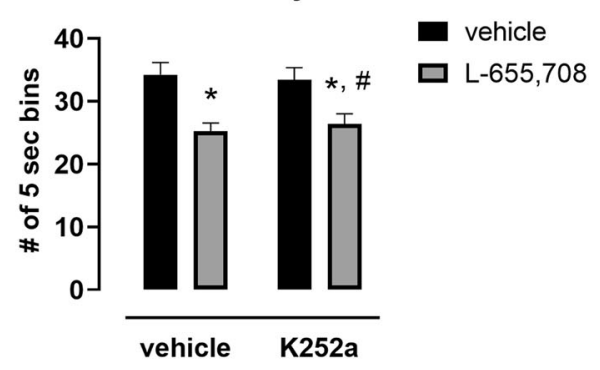

Climbing

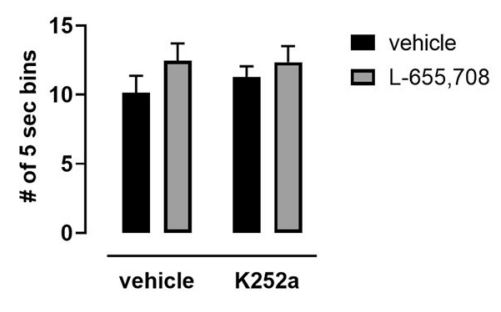

Fig. 4 The sustained AD-like effect of L-655,708 does not involve activation of TrkB receptor in the vHipp. a L-655,708 (3 mg/kg, i.p.) produced no significant increase in phosphorylation of TrkB $0.5 \mathrm{~h}$ - or $1 \mathrm{~h}$ following drug administration in male rats, $n=6$. $\mathbf{b}$ Blockade of TrkB phosphorylation in the vHipp did not prevent the sustained AD-like response to L-655,708 in male rats. Male rats were administered either vehicle or K252a $(0.5 \mathrm{ng}, 0.5 \mathrm{ul})$ directly into the vHipp followed by systemic administration of L-655,708 (3 mg/kg, i.p.) or vehicle. FST was performed 1 week following drug treatment. ${ }^{*} p<0.05$ compared to control vehicle, ${ }^{\#} p<0.05$ compared to K252a vehicle; $n=8-9$.

Despite its very promising effects for treating depression, $\mathrm{R}, \mathrm{S}$ ketamine is associated with potential for abuse as it can cause psychotomimetic side effects, such as pseudo- hallucinations, and impairments in cognition as well as in judgment $[43,44]$. In spite of the fact that the recently FDA-approved S-ketamine (esketamine) spray (Spravato ${ }^{\circledR}$ ) for TRD has been shown to improve depressive symptomatology $[45,46]$, some controversial results have been raised with regard to risk for suicide [47, 48]. Moreover, although no clinical trials to date have been published that test the effects of R-ketamine (arketamine) in improving depressive symptomatology, preclinical data in mice have suggested that arketamine seems more promising than esketamine $[49,50]$. An important consequence of the demonstrated efficacy of R,Sketamine is the search for similar but not identical drugs that might have less adverse effects like those of R,S-ketamine. As a5containing $\mathrm{GABA}_{\mathrm{A}}$ receptors are highly localized to the hippocampus in rats and humans $[19,51,52]$, a selective alpha5-GABANAM could reduce GABAergic inhibition onto glutamatergic neurons in the hippocampal output neurons, so as to produce AD-like effects. This has been shown by Thompson and his colleagues and others previously [30,31]. Furthermore, the side effect profile of such drugs is likely to be superior to that of R,S- ketamine as we have found L-655,708 not to produce psychotomimetic effects or to be self-administered in rats whereas $\mathrm{R}, \mathrm{S}$ ketamine did [31].

The expression of a5-subunit-containing $\mathrm{GABA}_{\mathrm{A}}$ receptors is higher in ventral compared to dorsal rat hippocampus [53]. This receptor has been proposed to be mainly extrasynaptic and located primarily in the dendritic fields of hippocampal CA1 and CA3 pyramidal cells in the rat $[16,19]$, as well as in humans [54]. However, this study and others have found significant effects of L655,708 in affecting phasic inhibitory currents [27]. These receptors play an important role in learning and memory processes [22, 54, 55]. Morphological studies and electrophysiological recordings in vivo and from ex vivo slices containing the hippocampus and prefrontal cortex have determined that pyramidal neurons of the ventral $\mathrm{CA} 1$ and subiculum form monosynaptic connections with pyramidal neurons in layers $2 / 3$ and 5 , as well as with inhibitory interneurons in the prelimibic (PL) and infralimbic (IL) regions of the mPFC in rodents [56-59]. Activation of a vHipp-mPFC pathway is necessary and sufficient for the AD-like effects of R,S-ketamine [13]. Our findings that injection of $L-655,708$ directly into the ventral hippocampus produces an AD-like effect and blocking AMPA receptors directly in the mPFC 


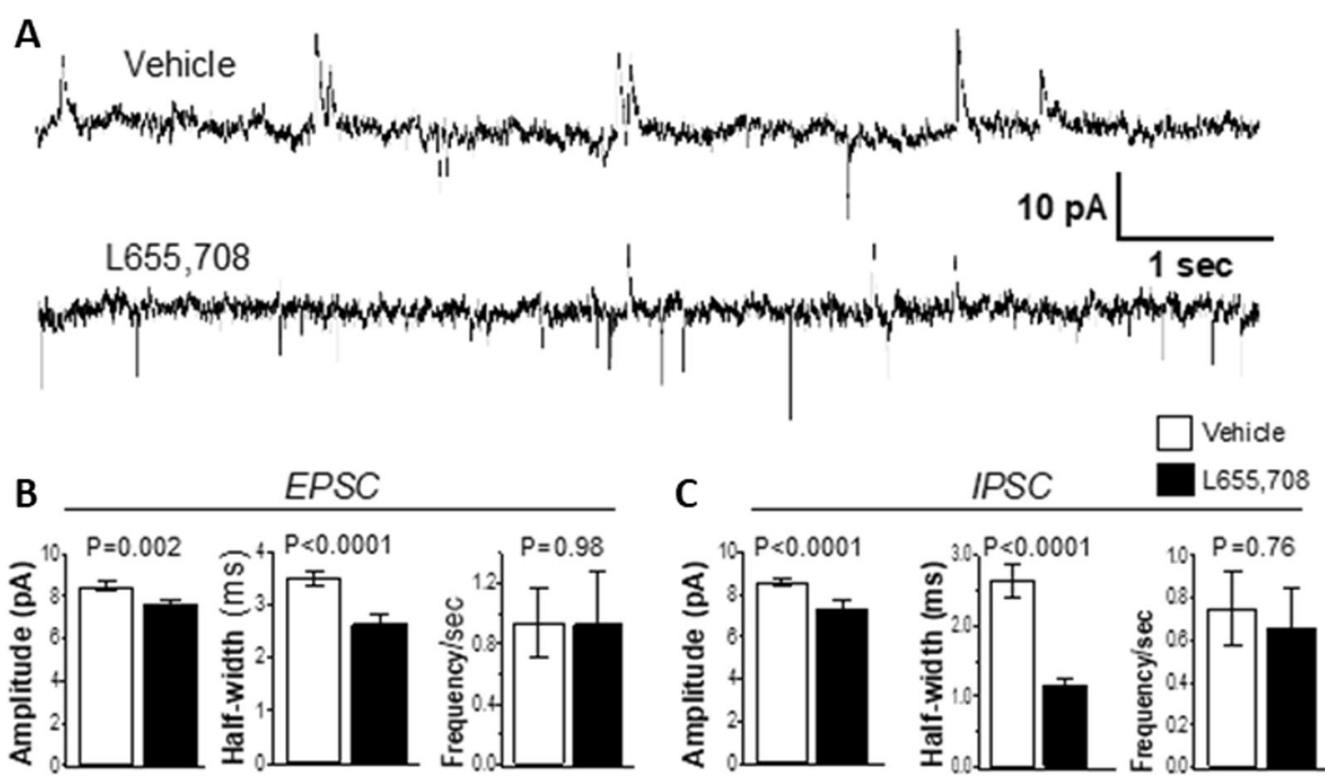

D
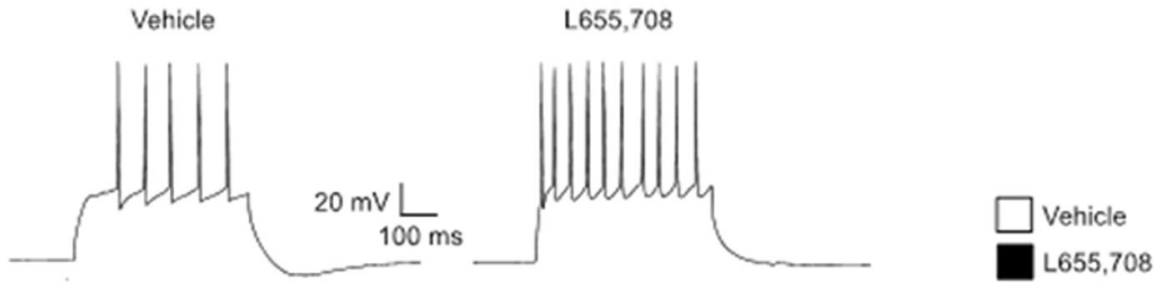

E
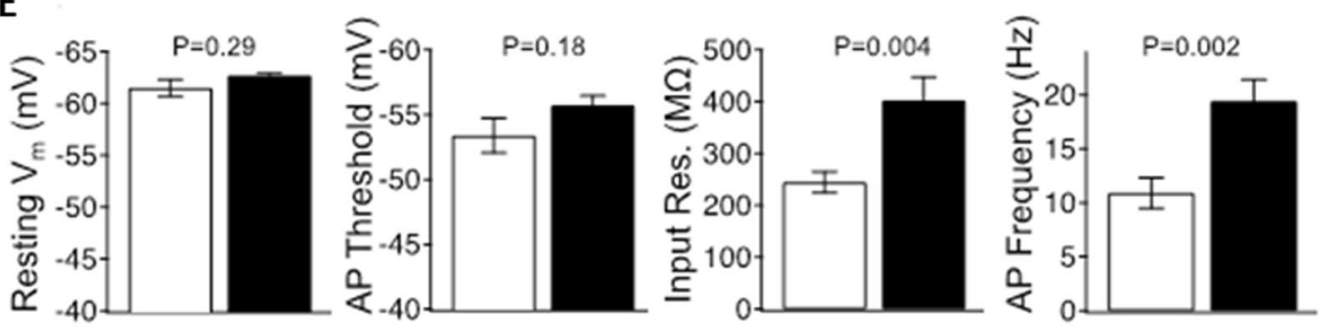

Fig. 5 L-655, 708 administration promotes sustained functional changes in vHipp pyramidal neuron activity measured 24h later. a-c. L-655,708 decreases duration of spontaneous IPSC currents in male rats. a Sample tracing of synaptic currents measured at -40 mV holding potential. Upward traces are IPSCs, downward traces are EPSCs. Traces are from rats previously treated with vehicle (upper trace) or L655,708 . b Summary data of EPSC from vehicle- (white bar) or L-655,708- treated rats (dark bar). There was a significant decrease in amplitude and half-width of EPSCs in rats treated with L-655,708. c Summary data of IPSC from vehicle (white bar) and L-655,708 (dark bar) treated rats. There was a significant decrease in amplitude and half-width in hippocampal slices from rats treated with $L-655.708$. $N=19$ neurons from 3 vehicle-treated rats, $N=27$ neurons from $4 \mathrm{~L}-655,708$ treated rats. $P$ values are from unpaired students $t$ test, assuming equal variance. d, e L-655,708 increases input resistance and action potential frequency. d Sample tracing of action potentials from 200 pA depolarizing current injections. e Summary data of action potential properties from vehicle- (white bar) and L-655,708- treated rats (dark bar). There was a significant increase in input resistance and action potential frequency in hippocampal slices from rats treated with $L-655,708$. $N=17$ neurons from 6 vehicle treated, $N=18$ neurons from $6 \mathrm{~L}-655,708$ treated. $P$ values are from unpaired students $t$ test, assuming equal variance.

blocks such an effect supports the idea that this pathway is also involved in its AD-like effect.

Aside from the AD-like effects of the selective a5-GABA-NAMs, there is a growing body of work showing that selective positive allosteric modulators of the a5-GABA $A_{A}$ receptor (a5-GABA-PAMs) also produce $A D$-like effects in the FST, as well as anxiolytic-like effects $[60,61]$. Moreover, such a5-GABA-PAMs were able to reverse stress- and age-induced deficits in working memory [61]. It is worth noting that the effects of selective a5-GABA-PAMs are achieved only while drugs are onboard, whereas the AD-like effects of selective a5-GABA-NAMs are sustained long after the drugs have been eliminated. The mechanisms by which both a5GABA-NAMs and a5-GABA-PAMs are eliciting the same behavioral result still need to be resolved. One possible theory by which both PAMs and NAMs would be useful to treat MDD is that both manipulations are hypothesized to increase the signal-to-noise ratio of hippocampal transmission, via different mechanisms $[62,63]$. As speculated in [62], for a5-GABA-PAMs, chronic administration would produce sustained decreases in tonic hippocampal activity (noise), without dramatically altering phasic activation of pyramidal neurons (the signal), resulting in an increase in signal-to-noise ratio. Conversely, as we observed, a5GABA-NAMs acutely decrease hippocampal GABAergic transmission onto CA1 pyramidal cells, which we theorize could cause a glutamatergic surge that in turn leads to glutamatergic plasticity. The hypothesis is that such glutamatergic plasticity results in a 
greater signal and, by extension, an increased signal-to-noise ratio [62].

The conclusion of the experiments shown in this study indicates that the AD-like effects of L-655,708 may be initiated by changes in $\mathrm{GABA}_{\mathrm{A}}$ receptor gating properties (Supplemental Fig. 4). This results in plasticity leading to sustained reduction of $G A B A_{A}$ transmission as well as increase in action potential frequency that ultimately mediates the sustained AD-like effects of L-655,708. The findings of a large change in half-width, but small change in amplitude of IPSC could be due to L-655,708 downregulating the levels of the alpha5-GABA $A_{A}$ receptor subunit at synapses. Recent studies indicate that changes in subunit composition, through downregulation of the alpha5 subunit, shortens chloride current openings and increases excitability of CA1 neurons [64]. Further studies would need to test such a hypothesis. By identifying the mechanisms by which systemic administration of a5-GABA receptor negative allosteric modulators recapitulate the therapeutic effects of R,S-ketamine without its psychotomimetic and abuserelated effects, it should be possible to provide novel, safe, and effective approaches for treating patients suffering with treatment refractory depression.

\section{FUNDING AND DISCLOSURE}

This work was supported by research grants MH113899 (FRC) from the National Institute of Mental Health, VA 2I01BX000559 from the Veterans Affairs (AF) and by a pilot project grant from the UTHSCSA Center for Biomedical Neuroscience (FRC). We thank Mr. Luis Arroyo for providing technical assistance. Some of the data had been published previously as abstract and/or poster form. Authors have no competing financial interests to disclose.

\section{AUTHOR CONTRIBUTIONS}

Designed the study FRC, DJL, AF and RB, Data collection VB, FRC, AMM, and RB, Analyzed data $V B, R B, F R C, A M M, D J L$ and $A F$, Wrote the manuscript FRC, AF and RB, Reviewed and Edited the manuscript VB, AMM, DJL, FRC AF and RB.

\section{ADDITIONAL INFORMATION}

Supplementary Information accompanies this paper at (https://doi.org/10.1038/ s41386-020-0772-2).

Publisher's note Springer Nature remains neutral with regard to jurisdictional claims in published maps and institutional affiliations.

\section{REFERENCES}

1. Cook SC, Wellman CL. Chronic stress alters dendritic morphology in rat medial prefrontal cortex. J Neurobiol. 2004;60:236-48.

2. Frodl $T$, Reinhold $E$, Koutsouleris $N$, Reiser M, Meisenzahl EM. Interaction of childhood stress with hippocampus and prefrontal cortex volume reduction in major depression. J Psychiatr Res. 2010;44:799-807.

3. Garrett JE, Wellman CL. Chronic stress effects on dendritic morphology in medial prefrontal cortex: sex differences and estrogen dependence. Neuroscience. 2009;162:195-207.

4. Squire LR, Stark CE, Clark RE. The medial temporal lobe. Annu Rev Neurosci. 2004;27:279-306

5. Videbech $P$, Ravnkilde B. Hippocampal volume and depression: a meta-analysis of MRI studies. Am J Psychiatry. 2004;161:1957-66.

6. Ishikawa A, Nakamura S. Ventral hippocampal neurons project axons simultaneously to the medial prefrontal cortex and amygdala in the rat. J Neurophysiol. 2006;96:2134-8.

7. Jay TM, Witter MP. Distribution of hippocampal CA1 and subicular efferents in the prefrontal cortex of the rat studied by means of anterograde transport of Phaseolus vulgaris-leucoagglutinin. J Comp Neurol. 1991;313:574-86.

8. Furmaga $\mathrm{H}$, Carreno FR, Frazer $\mathrm{A}$. Vagal nerve stimulation rapidly activates brainderived neurotrophic factor receptor TrkB in rat brain. PloS one. 2012;7:e34844.

9. Mayberg HS, Brannan SK, Tekell JL, Silva JA, Mahurin RK, McGinnis S, et al. Regional metabolic effects of fluoxetine in major depression: serial changes and relationship to clinical response. Biol Psychiatry. 2000;48:830-43.
10. Nibuya M, Nestler EJ, Duman RS. Chronic antidepressant administration increases the expression of CAMP response element binding protein (CREB) in rat hippocampus. J Neurosci: Off J Soc Neurosci. 1996;16:2365-72.

11. Autry $A E$, Adachi $M$, Nosyreva $E, N a$ ES, Los MF, Cheng PF, et al. NMDA receptor blockade at rest triggers rapid behavioural antidepressant responses. Nature. 2011;475:91-5

12. Duman RS, Li N, Liu RJ, Duric V, Aghajanian G. Signaling pathways underlying the rapid antidepressant actions of ketamine. Neuropharmacology. 2012;62:35-41.

13. Carreno FR, Donegan JJ, Boley AM, Shah A, DeGuzman M, Frazer A, et al. Activation of a ventral hippocampus-medial prefrontal cortex pathway is both necessary and sufficient for an antidepressant response to ketamine. Mol Psychiatry. 2016;21:1298-308.

14. Jett JD, Boley AM, Girotti M, Shah A, Lodge DJ, Morilak DA. Antidepressant-like cognitive and behavioral effects of acute ketamine administration associated with plasticity in the ventral hippocampus to medial prefrontal cortex pathway. Psychopharmacology. 2015;232:3123-33.

15. Sieghart W, Sperk G. Subunit composition, distribution and function of GABA(A) receptor subtypes. Curr Top medicinal Chem. 2002;2:795-816.

16. Caraiscos VB, Elliott EM, You-Ten KE, Cheng VY, Belelli D, Newell JG, et al. Tonic inhibition in mouse hippocampal CA1 pyramidal neurons is mediated by alpha5 subunit-containing gamma-aminobutyric acid type A receptors. Proc Natl Acad Sci USA. 2004;101:3662-7.

17. Magnin E, Francavilla R, Amalyan S, Gervais E, David LS, Luo X, et al. Inputspecific synaptic location and function of the alpha5 GABAA receptor subunit in the mouse CA1 hippocampal neurons. J Neurosci: Off J Soc Neurosci. 2019;39:788-801.

18. Stefanits H, Milenkovic I, Mahr N, Pataraia E, Hainfellner JA, Kovacs GG, et al. GABAA receptor subunits in the human amygdala and hippocampus: immunohistochemical distribution of 7 subunits. J Comp Neurol. 2018;526:324-48.

19. Sur C, Fresu L, Howell O, McKernan RM, Atack JR. Autoradiographic localization of alpha5 subunit-containing GABAA receptors in rat brain. Brain Res. 1999;822:265-70.

20. Brunig I, Scotti E, Sidler C, Fritschy JM. Intact sorting, targeting, and clustering of gamma-aminobutyric acid A receptor subtypes in hippocampal neurons in vitro. J Comp Neurol. 2002;443:43-55.

21. Christie SB, Miralles CP, De Blas AL. GABAergic innervation organizes synaptic and extrasynaptic GABAA receptor clustering in cultured hippocampal neurons. J Neurosci: Off J Soc Neurosci. 2002;22:684-97.

22. Crestani F, Keist R, Fritschy JM, Benke D, Vogt K, Prut L, et al. Trace fear conditioning involves hippocampal alpha5 GABA(A) receptors. Proc Natl Acad Sci USA. 2002;99:8980-5.

23. Fritschy JM, Johnson DK, Mohler $H$, Rudolph U. Independent assembly and subcellular targeting of $\mathrm{GABA}(\mathrm{A})$-receptor subtypes demonstrated in mouse hippocampal and olfactory neurons in vivo. Neurosci Lett. 1998;249:99-102.

24. Casula MA, Bromidge FA, Pillai GV, Wingrove PB, Martin K, Maubach K, et al. Identification of amino acid residues responsible for the alpha5 subunit binding selectivity of $L-655,708$, a benzodiazepine binding site ligand at the GABA(A) receptor. J Neurochemistry. 2001;77:445-51.

25. Quirk K, Blurton P, Fletcher S, Leeson P, Tang F, Mellilo D, et al. [3H]L-655,708, a novel ligand selective for the benzodiazepine site of GABAA receptors which contain the alpha 5 subunit. Neuropharmacology. 1996;35:1331-5.

26. Serwanski DR, Miralles CP, Christie SB, Mehta AK, Li X, De Blas AL. Synaptic and nonsynaptic localization of GABAA receptors containing the alpha5 subunit in the rat brain. J Comp Neurol. 2006;499:458-70.

27. Prenosil GA, Schneider Gasser EM, Rudolph U, Keist R, Fritschy JM, Vogt KE. Specific subtypes of GABAA receptors mediate phasic and tonic forms of inhibition in hippocampal pyramidal neurons. J Neurophysiol. 2006;96:846-57.

28. Salesse C, Mueller CL, Chamberland S, Topolnik L. Age-dependent remodelling of inhibitory synapses onto hippocampal CA1 oriens-lacunosum moleculare interneurons. J Physiol. 2011;589:4885-901.

29. Mohler $H$, Rudolph U. Disinhibition, an emerging pharmacology of learning and memory. F1000Research. 2017;6:101.

30. Fischell J, Van Dyke AM, Kvarta MD, LeGates TA, Thompson SM. Rapid antidepressant action and restoration of excitatory synaptic strength after chronic stress by negative modulators of Alpha5-containing GABAA receptors. Neuropsychopharmacol: Off Publ Am Coll Neuropsychopharmacol. 2015;40:2499-509.

31. Carreno FR, Collins GT, Frazer A, Lodge DJ. Selective pharmacological augmentation of hippocampal activity produces a sustained antidepressant-like response without abuse-related or psychotomimetic effects. Int J Neuropsychopharmacol / Off Sci J Collegium Int Neuropsychopharmacologicum. 2017;20:504-09.

32. Detke MJ, Rickels $M$, Lucki I. Active behaviors in the rat forced swimming test differentially produced by serotonergic and noradrenergic antidepressants. Psychopharmacology. 1995;121:66-72. 
33. Carreno FR, Frazer A. Activation of signaling pathways downstream of the brainderived neurotrophic factor receptor, TrkB, in the rat brain by vagal nerve stimulation and antidepressant drugs. Int J Neuropsychopharmacol/Off Sci J Collegium Int Neuropsychopharmacologicum. 2014;17:247-58.

34. Li N, Lee B, Liu RJ, Banasr M, Dwyer JM, Iwata M, et al. mTOR-dependent synapse formation underlies the rapid antidepressant effects of NMDA antagonists. Science. 2010;329:959-64.

35. Carreno FR, Ji LL, Cunningham JT. Altered central TRPV4 expression and lipid raft association related to inappropriate vasopressin secretion in cirrhotic rats. Am J Physiol Regulatory, Integr Comp Physiol. 2009;296:R454-66.

36. Porsolt RD, Anton G, Blavet N, Jalfre M. Behavioural despair in rats: a new model sensitive to antidepressant treatments. Eur J Pharmacol. 1978;47:379-91.

37. Belzung C. Innovative drugs to treat depression: did animal models fail to be predictive or did clinical trials fail to detect effects? Neuropsychopharmacol: Off Publ Am Coll Neuropsychopharmacol. 2014;39:1041-51.

38. Kara NZ, Stukalin Y, Einat H. Revisiting the validity of the mouse forced swim test: systematic review and meta-analysis of the effects of prototypic antidepressants. Neurosci Biobehav Rev. 2018;84:1-11.

39. Abdallah CG, Sanacora G, Duman RS, Krystal JH. Ketamine and rapid-acting antidepressants: a window into a new neurobiology for mood disorder therapeutics. Annu Rev Med. 2015;66:509-23.

40. Zanos P, Moaddel R, Morris PJ, Georgiou P, Fischell J, Elmer Gl, et al. NMDAR inhibition-independent antidepressant actions of ketamine metabolites. Nature. 2016;533:481-6.

41. Maeng S, Zarate CA Jr., Du J, Schloesser RJ, McCammon J, Chen G, et al. Cellular mechanisms underlying the antidepressant effects of ketamine: role of alphaamino-3-hydroxy-5-methylisoxazole-4-propionic acid receptors. Biol Psychiatry. 2008;63:349-52.

42. Volianskis A, France G, Jensen MS, Bortolotto ZA, Jane DE, Collingridge GL. Longterm potentiation and the role of $\mathrm{N}$-methyl-D-aspartate receptors. Brain Res. 2015;1621:5-16.

43. Bowdle TA, Radant AD, Cowley DS, Kharasch ED, Strassman RJ, Roy-Byrne PP. Psychedelic effects of ketamine in healthy volunteers: relationship to steady-state plasma concentrations. Anesthesiology. 1998;88:82-8.

44. Short B, Fong J, Galvez V, Shelker W, Loo CK. Side-effects associated with ketamine use in depression: a systematic review. lancet Psychiatry. 2018;5:65-78.

45. Daly EJ, Singh JB, Fedgchin M, Cooper K, Lim P, Shelton RC, et al. Efficacy and safety of intranasal esketamine adjunctive to oral antidepressant therapy in treatment-resistant depression: a randomized clinical trial. JAMA Psychiatry. 2018;75:139-48.

46. Popova V, Daly EJ, Trivedi M, Cooper K, Lane R, Lim P, et al. Efficacy and safety of flexibly dosed esketamine nasal spray combined with a newly initiated oral antidepressant in treatment-resistant depression: a randomized double-blind active-controlled study. Am J Psychiatry. 2019;176:428-38.

47. Perez-Esparza R, Kobayashi-Romero LF, Garcia-Mendoza AM, Lamas-Aguilar RM, Fonseca-Perezamador A. Promises and concerns regarding the use of ketamine and esketamine in the treatment of depression. Acta Psychiatr Scandinavica. 2019;140:182-3.
48. Schatzberg AF. A word to the wise about intranasal esketamine. Am J Psychiatry. 2019;176:422-4.

49. Yang C, Shirayama Y, Zhang JC, Ren Q, Yao W, Ma M, et al. R-ketamine: a rapidonset and sustained antidepressant without psychotomimetic side effects. Transl Psychiatry. 2015;5:e632.

50. Zhang JC, Li SX, Hashimoto K. R (-)-ketamine shows greater potency and longer lasting antidepressant effects than $\mathrm{S}(+)$-ketamine. Pharmacol Biochem Behav. 2014;116:137-41.

51. Howell O, Atack JR, Dewar D, McKernan RM, Sur C. Density and pharmacology of alpha5 subunit-containing $\mathrm{GABA}(\mathrm{A})$ receptors are preserved in hippocampus of Alzheimer's disease patients. Neuroscience. 2000;98:669-75.

52. Pirker S, Schwarzer C, Wieselthaler A, Sieghart W, Sperk G. GABA(A) receptors: immunocytochemical distribution of 13 subunits in the adult rat brain. Neuroscience. 2000;101:815-50.

53. Sotiriou E, Papatheodoropoulos C, Angelatou F. Differential expression of gamma-aminobutyric acid-a receptor subunits in rat dorsal and ventral hippocampus. J Neurosci Res. 2005;82:690-700.

54. Wainwright $A$, Sirinathsinghji DJ, Oliver KR. Expression of $\operatorname{GABA}(A)$ receptor alpha5 subunit-like immunoreactivity in human hippocampus. Brain Res Mol brain Res. 2000;80:228-32

55. Collinson N, Kuenzi FM, Jarolimek W, Maubach KA, Cothliff R, Sur C, et al. Enhanced learning and memory and altered GABAergic synaptic transmission in mice lacking the alpha 5 subunit of the GABAA receptor. J Neurosci: Off J Soc Neurosci. 2002;22:5572-80.

56. Anastasiades PG, Marlin JJ, Carter AG. Cell-type specificity of callosally evoked excitation and feedforward inhibition in the prefrontal cortex. Cell Rep. 2018;22:679-92.

57. Dembrow NC, Chitwood RA, Johnston D. Projection-specific neuromodulation of medial prefrontal cortex neurons. J Neurosci: Off J Soc Neurosci. 2010;30:16922-37.

58. Liu X, Carter AG. Ventral hippocampal inputs preferentially drive corticocortical neurons in the infralimbic prefrontal cortex. J Neurosci: Off J Soc Neurosci. 2018:38:7351-63.

59. Phillips ML, Robinson HA, Pozzo-Miller L. Ventral hippocampal projections to the medial prefrontal cortex regulate social memory. eLife. 2019;8:e44182.

60. Prevot TD, Li G, Cook JM, Sibille E. Insight into novel treatment for cognitive dysfunctions across disorders. ACS Chem Neurosci. 2019;10:2088-90.

61. Prevot TD, Li G, Vidojevic A, Misquitta KA, Fee C, Santrac A, et al. Novel benzodiazepine-like ligands with various anxiolytic, antidepressant, or procognitive profiles. Mol Neuropsychiatry. 2019;5:84-97.

62. Carreno FR, Lodge DJ, Frazer A. Ketamine: leading us into the future for development of antidepressants. Behav Brain Res. 2020;383:112532.

63. Prevot T, Sibille E. Altered GABA-mediated information processing and cognitive dysfunctions in depression and other brain disorders. Mol Psychiatry. 2020. https://doi.org/10.1038/s41380-020-0727-3.

64. Schulz JM, Knoflach F, Hernandez MC, Bischofberger J. Dendrite-targeting interneurons control synaptic NMDA-receptor activation via nonlinear alpha5GABAA receptors. Nat Commun. 2018:9:3576. 